\title{
Distinct Roles of Calcineurin-Nuclear Factor of Activated T Cells and Protein Kinase A-cAMP Response Element- Binding Protein Signaling in Presynaptic Differentiation
}

\author{
Tomoyuki Yoshida and Masayoshi Mishina \\ Department of Molecular Neurobiology and Pharmacology, Graduate School of Medicine, University of Tokyo, and Solution-Oriented Research for Science \\ and Technology, Japan Science and Technology Corporation, Tokyo 113-0033, Japan
}

\begin{abstract}
Synaptic vesicle accumulation and morphological changes are characteristic features of axon terminal differentiation during synaptogenesis. To investigate the regulatory mechanism that orchestrates synaptic molecules to form mature presynaptic terminals, we visualized a single axon terminal of zebrafish olfactory sensory neurons in vivo and examined the effects of the neuron-specific gene manipulations on the axon terminal differentiation. Synaptic vesicles visualized with vesicle-associated membrane protein 2 (VAMP2)enhanced green fluorescent protein (EGFP) fusion protein gradually accumulated in axon terminals, whereas the axon terminals visualized with GAP43 fused with EGFP remodeled from complex shapes with filopodia to simple shapes without filopodia from $50 \mathrm{~h}$ postfertilization (hpf) to $84 \mathrm{hpf}$. Expression of dominant-negative protein kinase A (PKA) or cAMP response element-binding protein (CREB) suppressed the VAMP2-EGFP punctum formation in axon terminals during synaptogenesis. Consistently, constitutively active PKA or CREB stimulated VAMP2-EGFP puncta formation. On the other hand, cyclosporine A treatment or suppression of nuclear factor of activated T cells (NFAT) activation prevented the axon terminal remodeling from complex to simple shapes during synaptogenesis. Consistently, expression of constitutively active calcineurin accelerated the axon terminal remodeling. These results suggest that calcineurin-NFAT signaling regulates axon terminal remodeling, and PKA-CREB signaling controls synaptic vesicle accumulation.
\end{abstract}

Key words: protein kinase A; CREB; calcineurin; NFAT; synapse formation; zebrafish

\section{Introduction}

Brain function is based on highly complex neural networks and their dynamics. Synaptic transmission requires elaborate structural specializations in both presynaptic and postsynaptic cells. The presynaptic terminal is hallmarked by a large number of synaptic vesicles orderly clustered around the active zone where synaptic vesicles dock and fuse (Dresbach et al., 2001). Synaptic vesicles are enriched with the proteins including vesicleassociated membrane protein 2 (VAMP2), synaptophysin, rab3A, synaptic vesicle protein 2, and synaptotagmin (Elferink and Scheller, 1993). In contrast, the active zone is enriched with several cytoskeletal proteins such as Piccolo/Aczonin and Bassoon (Garner et al., 2000). Many neurons synthesize synaptic machinery through intrinsic programs before cell-cell interac-

Received Sept. 9, 2004; revised Jan. 12, 2005; accepted Feb. 10, 2005.

This work was supported in part by research grants from the Japan Science and Technology Corporation and the Ministry of Education, Culture, Sports, Science and Technology of Japan. T.Y. was a recipient of the Fellowship for Young Scientists from the Japan Society for the Promotion of Science. We thank K. Kinomoto and A. Uotsu for help in zebrafish breeding, Dr. K. Kawakami for providing Tol2 mRNA and the plasmids pTol2000 and pT2KXIG, Dr. G. S. McKnight for the plasmids pCQ87/R196 and pMT-Rev ${ }^{\mathrm{AB}}$-neo, Dr. P. Mombaerts for the internal ribosomal entry site-tauGFP-LNL cassette, Dr. M. Kataoka for the plasmid VAMP2/pEGFP-N3, and Dr. G. R. Crabtree for the plasmid $\mathrm{pBJ}-\mathrm{CN} \triangle \mathrm{A}$. We are grateful to Dr. M. Ohtsuka for his encouragement and support.

Correspondence should be addressed to Dr. Masayoshi Mishina, Department of Molecular Neurobiology and Pharmacology, Graduate School of Medicine, University of Tokyo, Tokyo 113-0033, Japan. E-mail: mishina@m.u-tokyo.ac.jp.

DOI:10.1523/JNEUROSCI.3738-04.2005

Copyright $\odot 2005$ Society for Neuroscience $\quad 0270-6474 / 05 / 253067-13 \$ 15.00 / 0$ tions (Ahmari et al., 2000; Zhai et al., 2001). The initial interaction between the presynaptic and postsynaptic cells triggers intracellular signals that induce assembly of preexisting synaptic machinery and a series of events that locally alter the structures of both cells to form a stable synapse (Vardinon-Friedman et al., 2000). Presynaptic differentiation and maturation is accompanied often by characteristic features including synaptic vesicle accumulation in the axon terminal, active zone formation, and change in cytoskeletal and membranous organizations (Kullberg et al., 1977; Hamori and Somogyi, 1983; Dent et al., 1999).

Evidence is accumulating that several cell adhesion molecules such as $\beta$-neurexin, SynCAM, and $\mathrm{N}$-cadherin are involved in the axon terminal differentiation of cultured neurons (Scheiffele et al., 2000; Biederer et al., 2002; Togashi et al., 2002; Dean et al., 2003). In addition, target-derived factors such as WNT-7a, fibroblast growth factor (FGF) 22, and their downstream signals are important for presynaptic development (Hall et al., 2000; Tokuoka et al., 2002; Umemori et al., 2004). Furthermore, genetic approaches in Drosophila and Caenorhabditis elegans identified diverse genes involved in the presynaptic differentiation, including genes for a Ser/Thr protein kinase, a microtubule-associated protein, a ubiquitin ligase, and a scaffold protein (Jin, 2002). Although large numbers of molecules are probably involved in synaptogenesis, intracellular signaling that orchestrates them to form mature presynaptic terminals is poorly understood. Intracellular levels of $\mathrm{Ca}^{2+}$ and cAMP are involved in the regulation of 
axon pathfinding and the plastic modification of presynaptic function (Song and Poo, 1999; Poser and Storm, 2001). However, possible roles of $\mathrm{Ca}^{2+}$ and cAMP signaling in axon terminal differentiation during synaptogenesis remain unexamined.

To investigate the intracellular signaling that controls the axon terminal differentiation, we used the olfactory sensory neuron-specific gene manipulation system in transparent zebrafish embryos (Yoshida and Mishina, 2003). Using olfactory marker protein gene (omp) promoter (Pomp)-driven effectorreporter double-cassette vectors, we found that the expression of constitutively active protein kinase A (PKA) or cAMP response element (CRE)-binding protein (CREB) stimulated the formation of VAMP2-enhanced green fluorescent protein (EGFP) puncta in presynaptic terminals. Consistently, dominantnegative PKA (dnPKA) or CREB suppressed the VAMP2-EGFP punctum formation. On the other hand, the upregulation of calcineurin stimulated morphological remodeling of axon terminals, and the suppression of calcineurin or nuclear factor of activated $\mathrm{T}$ cells (NFAT) prevented the remodeling. These results suggest that calcineurin-NFAT and PKA-CREB signaling regulate the morphological remodeling and synaptic vesicle accumulation, respectively.

\section{Materials and Methods}

Animals. Zebrafish AB strain was used. Zebrafish embryos were raised at $28.5^{\circ} \mathrm{C}$ in embryo medium (EM) containing $17 \mathrm{~mm} \mathrm{NaCl}, 0.27 \mathrm{~mm}$ $\mathrm{CaCl}_{2}, 0.66 \mathrm{~mm} \mathrm{MgSO}_{4}, 0.4 \mathrm{~mm} \mathrm{KCl}$, and $1 \times 10^{-5} \%$ methylene blue.

Construction of zebrafish olfactory sensory neuron-specific expression vectors. The Ras farnesylation signal between the Bam HI and BglII sites of pEGFP-F (Clontech, Palo Alto, CA) was deleted to yield pEGFPd. The 1.0 $\mathrm{kb}$ DNA fragment carrying the EGFP coding sequence and the simian virus 40 (SV40) polyadenylation signal sequence (EGFP-SV40polyA) was obtained by PCR with primers ( $5^{\prime}$-GGATCCACCGGTCGCCACCATGG-3' and 5'-GTCGACGCTTACAATTTACGCG-3') using pEGFPd as a template. The $0.6 \mathrm{~kb}$ coding sequence of zebrafish GAP43 (GenBank accession number L27645) was obtained by reverse transcriptase-PCR (RT-PCR) using total RNA from $24 \mathrm{~h}$ postfertilization (hpf) zebrafish embryos with primers (5'-CCGGAATTCACATGTTGTGCTGCATCAGAAGAAC-3' and 5'-CGCGGATCCCGAACACTCTCCTCTGTGCC- $\left.3^{\prime}\right)$. The $0.4 \mathrm{~kb}$ coding sequence of rat VAMP2 was obtained by PCR with primers (5'-CCGGAATTCACATGTCGGCTACCGCTGC-3' and $5^{\prime}$-GACCGGTGGATCCGAAGTGCTGAAGTAAACGATG-3') using VAMP2/pEGFP-N3 (a gift from Dr. M. Kataoka, Shinshu University, Nagano, Japan) as a template. The $0.6 \mathrm{~kb}$ $B s p L U 11$ I-Bam HI fragment from the zebrafish GAP43 coding sequence, the $1.2 \mathrm{~kb} \mathrm{NcoI-BamHI}$ fragment from internal ribosomal entry sitetauGFP-LNL cassette (Rodriguez et al., 1999), and the $0.4 \mathrm{~kb}$ BspLU11I$B a m \mathrm{HI}$ fragment from the rat VAMP2 coding sequence were ligated with the $1.0 \mathrm{~kb}$ BamHI-SalI fragment from EGFP-SV40polyA to yield reporter genes, GAP43-EGFP, tau-EGFP, and VAMP2-EGFP, respectively. The GAP43-EGFP, tau-EGFP, and VAMP2-EGFP genes were ligated with the $1.4 \mathrm{~kb}$ EcoRI-BspLU11I fragment from the 5' upstream sequence of the zebrafish omp gene (Yoshida et al., 2002) and the $3.0 \mathrm{~kb}$ SalI-EcoRI fragment from pBluescript II SK + (Stratagene, La Jolla, CA) to yield Pomp-GG, Pomp-TG, and Pomp-VG, respectively. The $1.2 \mathrm{~kb}$ coding sequence of the constitutively active form of mouse calcineurin $(\mathrm{caCN})$ was obtained by PCR with primers (5'-TCTAGAACATGTCCGAGCCCAAGG-3' and 5'-GGGAATTCTCAGTAATCTGGAACATCGTATGGGTACATTTCCTTCCGGGCTGCGGC-3') using pBJ$\mathrm{CN} \Delta \mathrm{A}$ (Clipstone and Crabtree, 1992) as a template. The coding sequence of A-CREB was obtained as described previously by Ahn et al. (1998). The $0.35 \mathrm{~kb}$ coding sequence of the DNA binding domain of mouse CREB was obtained with primers (5'-TACGGTGGGCAGATTCTAGTGCCC- $3^{\prime}$ and $5^{\prime}$-TCTAGAAAATTAATCTGATTTGTGGC$3^{\prime}$ ) using mouse CREB cDNA as a template, whereas the $0.26 \mathrm{~kb}$ sequence encoding the VP16 activation domain was amplified with primers $\left(5^{\prime}\right.$ CCATGGGACACACGCGCAGACTG-3' and 5'-TAGAATCTGC-
CCACCGTACTCGTC-3') using pTet-On (Clontech) as a template. The VP16-CREB sequence was obtained by PCR using these two DNA fragments as templates. The $0.7 \mathrm{~kb}$ coding sequences of glutathione $S$ transferase (GST)-VIVIT and GST-control peptide (CP) were generated by PCR with primers 5' -TCATGACCCCTATACTAGGTTATTG-3' and 5' -TCTAGATCACTCCTCGTGGGGGCCGGTGATGACGATGACGGGGTGGGGGCCGGCCATGGTGGATCCACGCGGAACCAG-3' and with primers $5^{\prime}$-TCATGACCCCTATACTAGGTTATTG-3' and 5' -TCTAGATCACATGATGATCTCGCCGGGGGTGACGTGCTCGACGGCGGGGGGGCCGTGGATGGTGGATCCACGCGGAACCAG-3' using pGEX-2TK (Amersham Biosciences, Uppsala, Sweden) as a template, respectively; the sequences of VIVIT and CP peptides are MAGPHPVIVITGPHEE and IHGPPAVEHVTPGEIM, respectively. These PCR fragments were subcloned into pCRII-TOPO vector (Invitrogen, Grand Island, NY) or pBluescript II SK+ vector. The $1.2 \mathrm{~kb}$ EcoRI-BspLU11I fragment from the mouse caCN coding sequence, the $0.25 \mathrm{~kb} N c o \mathrm{I}-E c o \mathrm{RI}$ fragment from the ACREB coding sequence, the $0.6 \mathrm{~kb} \mathrm{NcoI-EcoRI} \mathrm{fragment} \mathrm{from} \mathrm{the} \mathrm{VP16-}$ CREB coding sequence, the $0.8 \mathrm{~kb} B s p \mathrm{HI}-E c o$ RI fragment from the GSTVIVIT coding sequence, and the $0.8 \mathrm{~kb} B s p \mathrm{HI}-E c o \mathrm{RI}$ fragment from the GST-CP coding sequence were ligated with the $2.7 \mathrm{~kb}$ NotI-BspLU11I fragment from the $5^{\prime}$ upstream sequence of the zebrafish omp gene (Yoshida et al., 2002), the $3.0 \mathrm{~kb} E c o \mathrm{RI}-B g l \mathrm{II}$ fragment from the $3^{\prime}$ downstream sequence of the zebrafish omp gene, and the $3.0 \mathrm{~kb}$ BamHI-NotI fragment from pBluescript II SK+ to yield Pomp-caCN, Pomp-ACREB, Pomp-VP16CREB, Pomp-GST-VIVIT, and Pomp-GST-CP, respectively. The $2.7 \mathrm{~kb}$ omp promoter-driven constitutively active form of mouse PKA $\alpha$ catalytic subunit expression vector (Pomp-PKA ${ }^{*}$ ) and dominant-negative form of the mouse type I regulatory subunit expression vector (Pomp-dnPKA) were described previously (Yoshida et al., 2002). Double-cassette vectors were constructed by inserting the effector cassettes into Pomp-GG, Pomp-TG, and Pomp-VG in the tail-to-head manner. The $2.0 \mathrm{~kb}$ DNA fragment encoding the amino acid residues 1-680 of mouse Bassoon (tom Dieck et al., 1998; Dresbach et al., 2003), the $0.8 \mathrm{~kb}$ enhanced yellow fluorescent protein (EYFP) coding sequence from pEYFP-N1 (Clontech), and $3.0 \mathrm{~kb} E c o$ RI-BglII fragment from the $3^{\prime}$ downstream sequence of the zebrafish omp gene were fused and placed under the control of the $2.7 \mathrm{~kb}$ NotI-BspLU11I fragment from the $5^{\prime}$ upstream sequence of the zebrafish omp gene to yield Pomp-Bassoon-EYFP. The $0.4 \mathrm{~kb}$ rat VAMP2 coding sequence, the $0.8 \mathrm{~kb}$ enhanced cyan fluorescent protein (ECFP) coding sequence from pECFP-N1 (Clontech), and the $3.0 \mathrm{~kb} \mathrm{3}$ ' downstream sequence of the zebrafish omp gene were fused and placed under the control of the $2.7 \mathrm{~kb} 5^{\prime}$ upstream sequence of the zebrafish omp gene to yield Pomp-VAMP2-ECFP. The $1.2 \mathrm{~kb}$ XhoI-BamHI fragment of Xenopus elongation factor $1 \alpha(\mathrm{EF} 1 \alpha)$ promoter from pT2KXIG (a gift from Dr. K. Kawakami, National Institute of Genetics, Mishima, Japan), the $0.7 \mathrm{~kb}$ Bam HI-BsrGI fragment from pECFP-N1, and the $3.5 \mathrm{~kb}$ XhoI$B s r$ GI fragment from pd2EGFP-N1 (Clontech) were ligated to yield PEF1 $\alpha$-d2ECFP. The EGFP coding sequence of pCRE-d2EGFP (Clontech) was replaced by the EYFP coding sequence to yield pCRE-d2EYFP. A linker sequence containing a Bam HI site was inserted into the NotI site of pCRE-d2EYFP to yield pB-CRE-d2EYFP. The $1.6 \mathrm{~kb}$ Bam HI fragment from $\mathrm{pB}$-CRE-d2EYFP was inserted into the BglII site of PEF1 $\alpha$-d2ECFP to yield PEF1 $\alpha$-d2ECFP-CRE-d2EYFP.

Microinjection of DNA into zebrafish embryos. Expression vectors were linearized by SpeI or XhoI and dissolved in $100 \mathrm{~mm} \mathrm{KCl}$ containing $0.05 \%$ phenol red. Approximately $0.2-0.5 \mathrm{nl}$ of the DNA solution at the concentrations of 50-100 $\mathrm{ng} / \mu \mathrm{l}$ was injected into the cytoplasm of the oneto four-cell embryos.

Generation of transgenic zebrafish lines. The $0.5 \mathrm{~kb}$ zebrafish $t b r 1 \mathrm{cDNA}$ fragment was obtained by RT-PCR using total RNA extracted from 24 hpf embryos with primers (5'-TCTGGTCTCGACCCAACG-3' and 5'GTCAACCGATCGATGTCGC-3'). By screening a zebrafish P1-derived artificial chromosome library (Incyte Genomics, St. Louis, MO) using the PCR fragment as a probe, we isolated the $t b r 1$ gene. The $0.8 \mathrm{~kb}$ EYFP coding sequence from pEYFP-N1 and the $0.2 \mathrm{~kb} \mathrm{BsrGI-XhoI} \mathrm{fragment}$ from EGFP-SV40polyA were fused and placed under the control of the 10 $\mathrm{kb}$ EcoRI-XhoI fragment containing the 5' upstream sequence and $12 \mathrm{bp}$ $\mathrm{N}$-terminal coding sequence of the zebrafish $t b r 1$ gene to yield PtbrEYFP. The $0.4 \mathrm{~kb} P v u \mathrm{II}$ fragment from pBluescript II SK + carrying multicloning site was inserted between the PvuII and SnaBI sites of pGBT9 
vector (Clontech) to yield pGBT-MCS. The 4.7kb KpnI-SacI fragment from pTol2000 (Kawakami and Noda, 2004) was inserted between the KpnI and SacI sites of pGBT-MCS to yield pGBT-T2K. The $11 \mathrm{~kb}$ EcoRIApaI fragment from Ptbr-EYFP was inserted between the EcoRI and ApaI sites of pGBT-T2K to yield pGBT-T2 $\delta$-tbr-EYFP. The $6.9 \mathrm{~kb}$ NotI-XhoI fragment from Pomp-VAMP2-ECFP was inserted between the NruI and XhoI sites of pTol2000 to yield pT2 $\delta$-omp-VAMP2-ECFP. Approximately $0.2-0.5 \mathrm{nl}$ of solution containing $50-100 \mathrm{ng} / \mu \mathrm{l} \mathrm{pGBT-T2} \delta$-tbrEYFP and pT2 $\delta$-omp-VAMP2-ECFP, $25 \mathrm{ng} / \mu \mathrm{l}$ Tol 2 mRNA (gift from Dr. Kawakami), $100 \mathrm{~mm} \mathrm{KCl}$, and $0.05 \%$ phenol red was injected into zebrafish fertilized eggs. Injected fish were maintained to sexual maturity and crossed with wild-type fish to examine the transmission of the transgene to the next generation. For observation of development of neural contacts in the olfactory system, F1 fish of Ptbr-EYFP and PompVAMP2-ECFP lines were crossed.

Immunohistochemistry. Zebrafish embryos at 60 and 84 hpf of the omp promoter-driven VAMP2-ECFP transgenic line were frozen in OCT (Tissue-Tek, Miles, Elkhart, IN), sectioned at a $10 \mu \mathrm{m}$ thickness, and then fixed with $4 \%$ paraformaldehyde for $30 \mathrm{~min}$ at room temperature. After the sections had been washed with PBS and blocked with $2 \%$ bovine serum albumin in PBS for $1 \mathrm{~h}$, they were incubated with the rabbit anti-GFP antibody (1:2000; Molecular Probes, Eugene, OR) and mouse anti-syntaxin antibody (1:200; Sigma, St. Louis, MO) overnight at room temperature in blocking solution. Samples were visualized with antimouse IgG-Alexa Fluor 546 (1:1000; Molecular Probes) and anti-rabbit IgG-Alexa Fluor 488 (1:1000; Molecular Probes) for $1 \mathrm{~h}$ at room temperature.

Microscopy. Zebrafish embryos expressing reporter genes in olfactory sensory neurons at $28-29 \mathrm{hpf}$ were screened by a fluorescent microscope using NIBA filter (Olympus, Tokyo, Japan). Screened embryos were then mounted in $1 \%$ low-melting point agarose in EM containing $0.02 \%$ 3 -aminobenzoic acid ethyl ester (tricaine; Sigma) with their heads toward the glass bottom of a dish at 36, 60, and $84 \mathrm{hpf}$. Embryos were imaged by a MRC-1024 confocal microscope (Bio-Rad, Hercules, CA) with an argon laser using a water immersion LUMPlanFL/IR2 $60 \times$ objective lens (Olympus): zoom setting, 5.0 for single axon terminal; Z-step, 1-2 $\mu \mathrm{m}$; image size, $512 \times 512$ pixels. BODIPY505/515 labeling of embryos was performed as described by Dynes and Ngai (1998). The EYFP and ECFP signals in zebrafish embryos were imaged by the Radiance 2100 confocal scanning system (Bio-Rad) using a Nikon $60 \times$ water lens [numerical aperture (NA), 1.00]: zoom setting, 1.0; Z-step, $4 \mu \mathrm{m}$; image size, $512 \times 512$ pixels.

Cyclosporine A treatment. Zebrafish embryos injected with Pomp-GG or Pomp-VG were dechorionated and soaked in the EM containing $0.1 \%$ ethanol with or without $100 \mu \mathrm{M}$ suspension of cyclosporine A from 30 to $84 \mathrm{hpf}$. Treated embryos were mounted in 1\% low-melting agarose in EM at 60 and $84 \mathrm{hpf}$ for microscopy.

CRE reporter gene assay. PEF1 $\alpha$-d2ECFP-CRE-d2EYFP-injected embryos were mounted in 1\% low-melting agarose in EM at 24, 36, 48, 60, 72 , and $84 \mathrm{hpf}$. ECFP-positive cells in the olfactory placode were imaged by the Radiance 2100 confocal scanning system (Bio-Rad) using a Nikon $60 \times$ water lens (1.00 NA): zoom setting, 1.0; Z-step, $3 \mu \mathrm{m}$; image size, $512 \times 512$ pixels. Power, gain, and iris setting of argon and heliumcadmium lasers were fixed through all the image acquisitions (laser power, $80 \%$; gain, $80 \%$; iris, 5 ; sequential mode).

Image processing. All quantitative measurements were made on the computer screen using the NIH Image 1.62 in the blind manner with respect to the expression vectors injected. For measurements of axon terminal morphology and VAMP2-EGFP puncta, z series optical sections were projected by the brightest point method and smoothened by the rank filter method. The outline of an axon terminal was traced from the first branch point or from the point where axonal width was three or more times wider than that of the axon shaft. The trace and the enclosed region were defined as the perimeter and area of the axon terminals, respectively. The complexity was given by dividing the square of the perimeter by the area. The stretch of the axon terminal was determined as the distance between the two furthest points within the area. The VAMP2-EGFP punctum was defined as an area larger than five pixels in which the intensity of VAMP2-EGFP signals was five or more times stronger than that of nonvaricose and nonpunctate axonal shaft on the same axon. Axons longer than $10 \mu \mathrm{m}$ were used for measurements. Expression levels of d2ECFP and d2EYFP in each cell were measured as the optical mean density within a circle with $6 \mu \mathrm{m}$ diameter enclosing the cell body. Statistical significance was evaluated by two-way ANOVA. When the interaction was significant, unpaired $t$ test or Dunnett's test was used. One-way ANOVA was used for the statistical analysis of developmental changes of the axon terminal morphology, VAMP2-EGFP puncta, and CRE-mediated d2EYFP expression.

\section{Results}

\section{Development of zebrafish olfactory sensory neuron} projection in the olfactory bulb

Axons of zebrafish olfactory sensory neurons begin to extend toward the olfactory bulb at $\sim 22 \mathrm{hpf}$, reach the target sites, and stop the extension at $\sim 50 \mathrm{hpf}$ (Dynes and Ngai, 1998; Yoshida et al., 2002). Then, a stereotyped pattern of glomeruli in the olfactory bulb, the anatomical basis for an olfactory sensory map (Ressler et al., 1994; Vassar et al., 1994; Mombaerts et al., 1996; Friedrich and Korsching, 1997), is manifested between 2 d postfertilization (dpf) and $3.5 \mathrm{dpf}$ (Wilson et al., 1990; Dynes and Ngai, 1998). To confirm the synaptogenesis period, we monitored the axon terminal development of olfactory sensory neurons using olfactory sensory neuron-specific omp promoter (Yoshida et al., 2002) and VAMP2 fused with ECFP as a well characterized marker of synaptic vesicles (Miesenbock et al., 1998; Nonet, 1999; Ahmari et al., 2000). In the developing olfactory bulb, the target areas for olfactory sensory neurons are visualized by BODIPY dye as plaque-like structures at $\sim 50 \mathrm{hpf}$, and these structures grow to form a stereotyped pattern of glomeruli at $84 \mathrm{hpf}$, as described by Dynes and Ngai (1998). In transgenic fish, the omp promoter directed the expression of VAMP2-ECFP in olfactory sensory neurons from $22 \mathrm{hpf}$, as described previously (Yoshida et al., 2002). The weak VAMP2-ECFP signals were distributed in cell bodies and axons at $36 \mathrm{hpf}$, a stage when axons of olfactory sensory neurons actively extended in the olfactory bulb (Fig. 1A). BODIPY dye staining showed no neuropil-like acellular structures in the olfactory bulb at $36 \mathrm{hpf}$ (Fig. 1 A). At $50 \mathrm{hpf}$, BODIPY-labeled structures appeared in the olfactory bulb, and several of them merged with VAMP2-ECFP signals in olfactory neuron axon terminals (Fig. 1C, arrow). Accumulation of VAMP2-ECFP signals in the axon terminal within BODIPYlabeled areas and enlargement of BODIPY-labeled structures further proceeded at $60 \mathrm{hpf}$ (Fig. $1 \mathrm{E}$, arrows). Intense VAMP2-ECFP signals merged with BODIPY-labeled glomeruli at $84 \mathrm{hpf}$ (Fig. $1 G$, arrows). Moreover, in transgenic embryos carrying the T-brain 1 gene, promoter-driven EYFP gene, and the omp promoter-driven VAMP2-ECFP gene, VAMP2-ECFP signals of olfactory sensory neuron axon terminals and EYFP signals of the target cell dendrites in the olfactory bulb became merged by 50 hpf (Fig. $1 B, D, F, H$ ). These observations confirmed that the synapse formation between olfactory sensory neurons and postsynaptic cells in the olfactory bulb proceeded between $\sim 50$ and 84 hpf.

\section{Synaptic vesicle accumulation in axon terminals of olfactory sensory neurons}

Using VAMP2-EGFP as a reporter and microinjection technique to visualize a single neuron (Yoshida and Mishina, 2003), we then examined the development of synaptic vesicle accumulation in axon terminals of individual olfactory neurons. In embryos injected with the control Pomp-VG vector carrying the omp promoter-driven VAMP2-EGFP construct (Fig. 2A, top), VAMP2-EGFP signals were distributed widely along the axon 

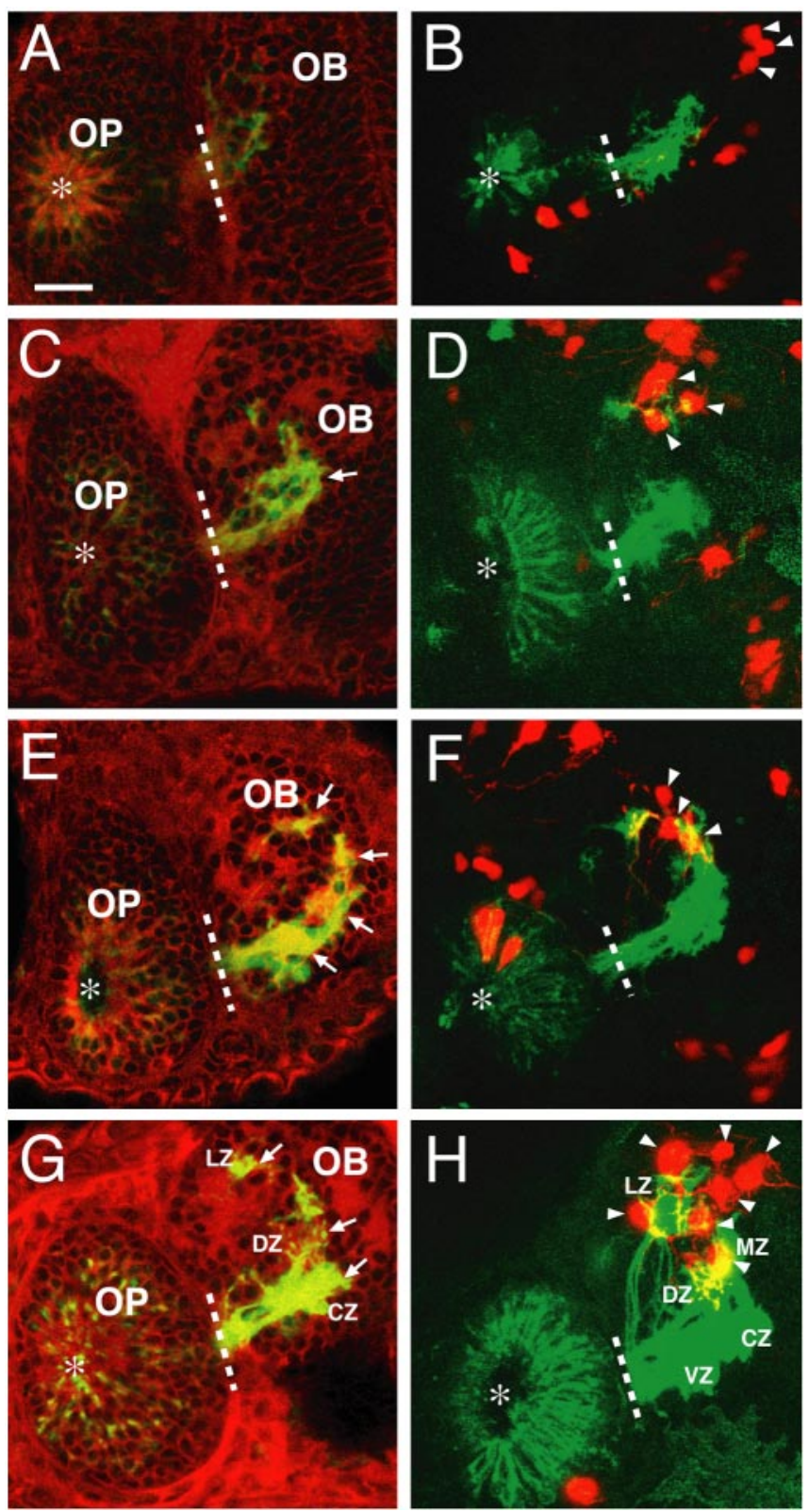

Figure 1. Development of connections between olfactory sensory neurons and target neurons in the dorsal olfactory bulb in living zebrafish. $A, C, E, G$, Frontal views of the right olfactory organ of a BODIPY-labeled zebrafish embryo carrying the omp promoter-driven VAMP2-ECFP transgene at $36 \mathrm{hpf}(\boldsymbol{A}), 50 \mathrm{hpf}(\boldsymbol{C}), 60 \mathrm{hpf}(\boldsymbol{E})$, and $84 \mathrm{hpf}(\boldsymbol{G})$. Each panel is a single optical section. VAMP2-ECFP (green) and BODIPY505/515 (red) signals were imaged with a heliumcadmium (HeCd) and an argon (Ar) laser, respectively. Arrows point to BODIPY-labeled areas merging with VAMP2-ECFP signals in olfactory neuron axon terminals. $\boldsymbol{B}, \boldsymbol{D}, \boldsymbol{F}, \boldsymbol{H}$, Frontal views of the right olfactory organ of a zebrafish embryo carrying both the omp promoter-driven VAMP2-ECFP and tbr 1 promoter-driven EYFP transgenes at $36 \mathrm{hpf}(\boldsymbol{B}), 50 \mathrm{hpf}(\boldsymbol{D}), 60 \mathrm{hpf}(\boldsymbol{F})$, and $84 \mathrm{hpf}(\boldsymbol{H})$. These composite images were generated from 15-20 $\mathrm{z}$-series optical sections. VAMP2-ECFP (green) and EYFP (red) signals were imaged with a HeCd and an Ar laser, respectively. Arrowheads indicate EYFP-positive round cells in the dorsal olfactory bulb. Asterisks indicate the nasal pit, and dashed lines indicate the boundary between olfactory placode and olfactory bulb. $\mathrm{OB}$, Olfactory bulb; $\mathrm{OP}$, olfactory placode. $\mathrm{CZ}, \mathrm{DZ}, \mathrm{LZ}, \mathrm{MZ}$, and VZ indicate the central, dorsal, lateral, medial, and ventral zones of glomeruli, respectively. Scale bar, $20 \mu \mathrm{m}$.

and in the growth cone at $36 \mathrm{hpf}$ (Fig. 2D) and then became gradually restricted and punctate within the axon terminals at 60 hpf (Fig. 2E). At $84 \mathrm{hpf}$, intense signals were localized in the axon terminals (Fig. $2 F$ ).

Punctate signals of VAMP2-ECFP in the axon terminals merged well with signals of Bassoon-EYFP, a presynaptic marker (tom Dieck et al., 1998; Dresbach et al., 2003) at $50 \mathrm{hpf}$ and thereafter (Fig. 2B). Moreover, VAMP2-ECFP puncta merged well with immunoreactive signals of endogenous syntaxin, one of target membrane soluble $\mathrm{N}$-ethylmaleimide-sensitive factor (NSF) attachment protein receptor proteins, at 60 and $84 \mathrm{hpf}$ (Fig. 2C). These analyses suggest that punctate signals of VAMP2-ECFP localized near the active zone of nerve terminals. In $>90 \%$ of embryos at $84 \mathrm{hpf}$, the intensity of VAMP2-EGFP signals in the axon terminals was more than five times stronger than that in the axonal shaft. Thus, we measured the developmental changes in the area in which the intensity of VAMP2EGFP signals was five or more times stronger than that of the axonal shaft as the VAMP2-EGFP punctum. In control olfactory neurons of Pomp-VG-injected embryos, the punctate area per axon markedly increased between 36 and $60 \mathrm{hpf}$ and further increased between 60 and $84 \mathrm{hpf}$ (one-way ANOVA; $p=3.4 \times$ $10^{-11}$ ) (Fig. $2 G-I, P$ ). Thus, the accumulation and punctum formation of VAMP2-EGFP signals during development are good indicators of the axon terminal maturation.

\section{Constitutively active PKA promotes VAMP2-EGFP punctum formation in axon terminals}

We next examined the effects of PKA and calcineurin signaling on synaptic vesicle accumulation during development using the double-cassette vector strategy (Yoshida et al., 2002). It is known that a constitutively active form of mouse PKA $\alpha$ catalytic subunit $\left(\mathrm{PKA}^{\star}\right)$ (Orellana and McKnight, 1992) stimulates PKA signaling in zebrafish embryos (Hammerschmidt et al., 1996). A constitutively active form of mouse calcineurin (Clipstone and Crabtree, 1992) stimulates calcineurin signaling in Xenopus embryos (Nishinakamura et al., 1997) and shares 88\% amino acid identity with the corresponding region of the zebrafish counterpart. We thus constructed expression vectors, Pomp-VG-caCN and Pomp-VG-PKA*, by linking the omp promoter-driven expression vectors for $\mathrm{caCN}$ and $\mathrm{PKA}^{*}$ with the omp promoter-driven VAMP2-EGFP fusion protein gene in the tail-to-head manner, respectively (Fig. $2 A$ ). Injection of these double-cassette vectors into zebrafish embryos enabled the expression of the effector molecules ( $\mathrm{caCN}$ and $\mathrm{PKA}^{*}$ ) together with the reporter (VAMP2-EGFP) in the same olfactory neurons. Olfactory sensory neurons in zebrafish embryos injected with the VAMP2EGFP expression vector served as a control.

There were significant differences in the punctate area per olfactory sensory neuron axon among Pomp-VG-, Pomp-VGcaCN-, and Pomp-VG-PKA*-injected embryos (two-way ANOVA; expression vector effect, $p=0.005$; age $\times$ expression vector interaction, $p=0.06$ ) (Fig. $2 D-F, J-P$ ). The VAMP2EGFP punctate area in the axon terminals of Pomp-VG-PKA*injected embryos were significantly larger than those of control Pomp-VG-injected embryos at $36 \mathrm{hpf}$ (Dunnett's test; $p=0.007$ ) (Fig. $2 M, P$ ). These results suggest that the stimulation of PKA signaling promoted the VAMP2-EGFP punctum formation in the axon terminals of olfactory sensory neurons. In contrast to the strong effects of constitutively active PKA, the expression of $\mathrm{caCN}$ did not affect the VAMP2-EGFP punctate area (Fig. $2 J-L, P)$.

Because $\mathrm{PKA}^{*}$ disturbed the axon projection of olfactory sensory neurons (Yoshida et al., 2002), we examined the effects of $\mathrm{PKA}^{\star}$ and $\mathrm{caCN}$ on the terminal reach value, that is, the distance from the nasal pit to the axon terminal of olfactory sensory neurons. For visualizing dendrites and axon terminals of olfactory neurons, the tau-EGFP fusion reporter gene was fused to the 
A

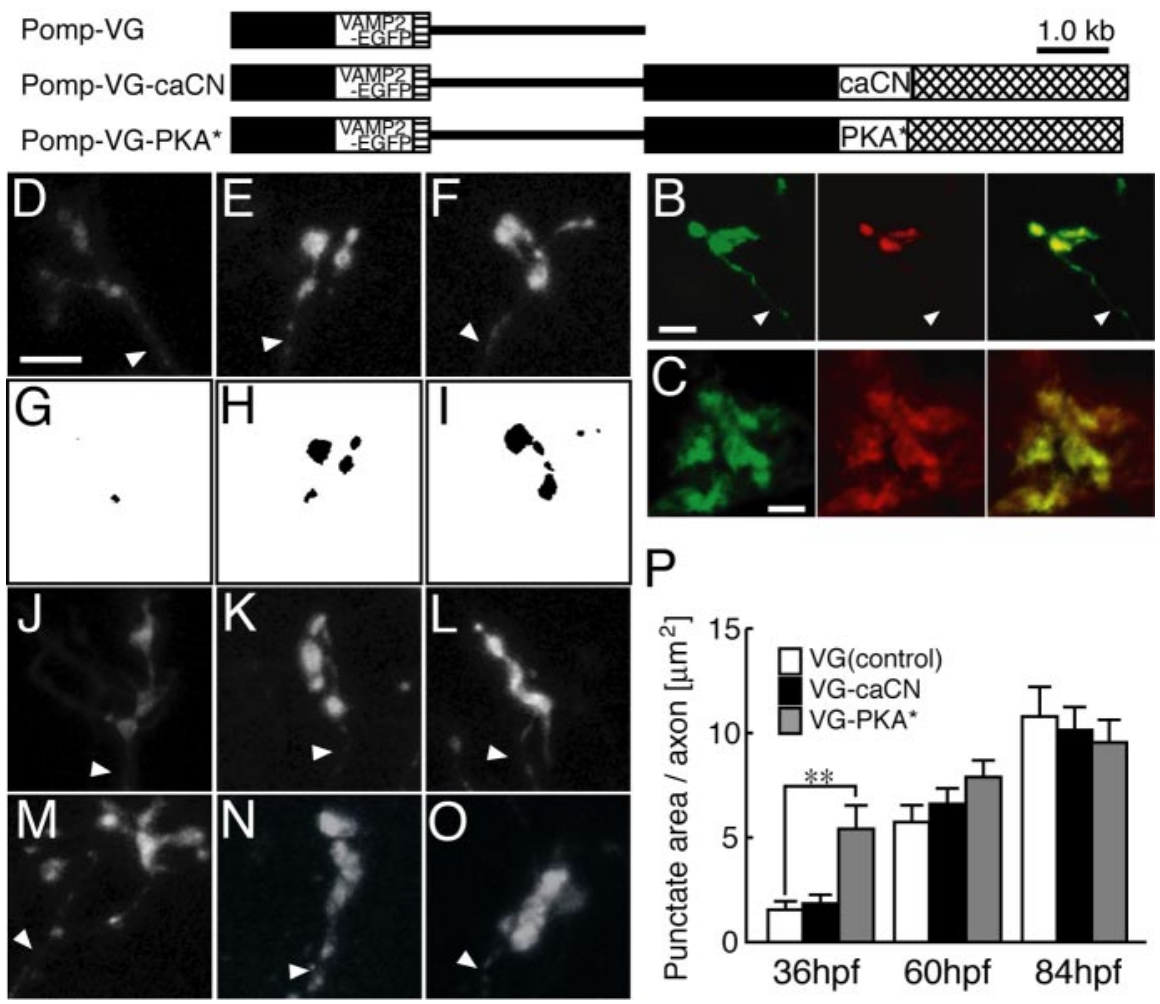

Figure 2. Effects of constitutively active calcineurin and constitutively active PKA on the development of VAMP2-EGFP puncta in axon terminals of olfactory sensory neurons. $\boldsymbol{A}, 0 \mathrm{mp}$ promoter-driven expression vectors for VAMP2-EGFP (top), for caCN and VAMP2-EGFP (middle), and for PKA* and VAMP2-EGFP (bottom) in olfactory sensory neurons. Black boxes, The omp promoter; cross-hatched boxes, the $3^{\prime}$ downstream sequence of the omp gene; hatched boxes, SV40 polyadenylation signal sequence; lines, pBluescript II SK+ $\boldsymbol{B}$, A single axon terminal of an olfactory sensory neuron in a zebrafish embryo injected with omp promoterdriven VAMP2-EGFP and Bassoon-EYFP vectors at $50 \mathrm{hpf}$. VAMP2-ECFP (left; green) and Bassoon-EYFP (middle; red) signals were merged on the right. Arrowheads point to axonal shafts. Scale bar, $5 \mu \mathrm{m}$. C, Confocal fluorescent images of immunostaining with anti-GFP (left; green) and anti-syntaxin (middle; red) antibodies in the olfactory bulb from an omp promoter-driven VAMP2-ECFP transgenic fish embryo at $60 \mathrm{hpf}$. Merged image is on the right. Scale bar, $10 \mu \mathrm{m}$. $\boldsymbol{D}-\boldsymbol{F}$, Representative VAMP2-EGFP signals in axon terminals of olfactory sensory neurons in Pomp-VG-injected embryos at $36 \mathrm{hpf}(\boldsymbol{D}), 60 \mathrm{hpf}(\boldsymbol{E})$, and $84 \mathrm{hpf}(\boldsymbol{F})$. Scale bar, 5 $\mu \mathrm{m}$. G-I, The threshold images of VAMP2-EGFP signals in $\boldsymbol{D}-\boldsymbol{F}$ for evaluation of VAMP2-EGFP puncta. $\boldsymbol{J}-\mathbf{0}$, Representative VAMP2-EGFP signals in axon terminals of olfactory sensory neurons in zebrafish embryos injected with Pomp-VG-caCN $(\boldsymbol{J}-\boldsymbol{L})$ or Pomp-VG-PKA* $(\boldsymbol{M}-\mathbf{0})$ at $36 \mathrm{hpf}(\boldsymbol{J}, \boldsymbol{M}), 60 \mathrm{hpf}(\boldsymbol{K}, \boldsymbol{N})$, and $84 \mathrm{hpf}(\boldsymbol{L}, \mathbf{0})$. Arrowheads point to axonal shafts. $\boldsymbol{P}$, The area of VAMP2-EGFP puncta in axon terminals of olfactory sensory neurons in zebrafish embryos injected with Pomp-VG (open bars), Pomp-VG-caCN (black bars), and Pomp-VG-PKA* (gray bars) expression vectors at 36, 60, and 84 hpf. Pomp-VG, $n=37,26$, and 30 at 36, 60, and $84 \mathrm{hpf}$, respectively, 21-23 embryos; Pomp-VG-caCN, $n=40,34$, and 34 at 36, 60, and 84 hpf, respectively, 24-26 embryos; Pomp-VG-PKA* $, n=25,37$, and 39 at 36, 60, and $84 \mathrm{hpf}$, respectively, $20-22$ embryos. All values represent mean \pm SEM. ${ }^{* *} p<0.01$.

caCN and $\mathrm{PKA}^{\star}$ effector genes to yield Pomp-TG-caCN and Pomp-TG-PKA* vectors. At $60 \mathrm{hpf}$, when axon terminals were at the target sites, terminal reach values of Pomp-TG-caCNinjected embryos $(97.9 \pm 3.3 \mu \mathrm{m}$; mean \pm SEM; $n=15$; five embryos) were comparable with those of control Pomp-TGinjected embryos ( $97.1 \pm 3.8 \mu \mathrm{m} ; n=28 ; 11$ embryos; Dunnett's test; $p=0.98)$. On the other hand, terminal reach values of Pomp-TG-PKA*-injected embryos $(108.1 \pm 3.4 \mu \mathrm{m} ; n=28$; nine embryos) were slightly larger than those of control PompTG-injected embryos (Dunnett's test; $p=0.048$ ). These results suggest that $\mathrm{caCN}$ exerted little effect on the axon projection of olfactory sensory neurons, but $\mathrm{PKA}^{*}$ appeared to induce overshooting of the axon terminals. Despite the slight augmenting effect on terminal reach values, $\mathrm{PKA}^{\star}$ stimulated the VAMP2EGFP punctum formation.
Dominant-negative PKA suppresses VAMP2-EGFP punctum formation in axon terminals

To further examine the physiological significance of PKA signaling in synaptic vesicle accumulation at axon terminals of olfactory sensory neurons, we tested the effects of endogenous PKA suppression. It is known that a dominant-negative form of the mouse type I regulatory subunit of PKA (Clegg et al., 1987) suppresses PKA signaling in zebrafish embryos (Hammerschmidt et al., 1996). We thus placed dnPKA in the effector-reporter cassette to yield Pomp-VG-dnPKA (Fig. 3A). The expression of dnPKA affected the developmental changes in the VAMP2-EGFP punctate area (two-way ANOVA; expression vector effect, $p=0.0002$; age $\times$ expression vector interaction, $p=0.023$ ) (Fig. $3 B-H$ ). The VAMP2-EGFP punctate area in axon terminals of Pomp-VGdnPKA-injected embryos was significantly smaller than that of control Pomp-VGinjected embryos at 60 and $84 \mathrm{hpf}$ ( $t$ test; $p=0.001$ and 0.022 , respectively) (Fig. $3 F-H)$. Our previous study showed that the expression of dominant-negative PKA in the olfactory neuron exerted little effect on the terminal reach of olfactory sensory neurons at $50 \mathrm{hpf}$ when axons stopped extension in the olfactory bulb (Yoshida et al., 2002). These results suggest that the suppression of endogenous PKA signaling hindered the VAMP2-EGFP punctum formation in axon terminals of olfactory sensory neurons during the period of synaptogenesis.

\section{CREB regulates VAMP2-EGFP punctum} formation in axon terminals

One of major PKA target proteins is CREB (Lonze and Ginty, 2002). We thus examined the effects of suppression and activation of CREB on VAMP2-EGFP punctum formation using A-CREB as a dominantnegative inhibitor of CREB (Ahn et al., 1998) and VP16-CREB as a constitutively active CREB (Yan et al., 1994), respectively. The A-CREB and VP16-CREB genes were placed in the effector-reporter cassette to yield Pomp-VG-ACREB and Pomp-VG-VP16CREB, respectively (Fig. $4 A$ ).

There were significant differences in the punctate area per olfactory sensory neuron axon among Pomp-VG-, Pomp-VGACREB-, and Pomp-VG-VP16CREB-injected embryos (twoway ANOVA; expression vector effect, $p=8.4 \times 10^{-12}$; age $\times$ expression vector interaction, $p=0.02$ ) (Fig. $4 B-K$ ). The VAMP2-EGFP punctate area in axon terminals of Pomp-VGACREB-injected embryos was significantly smaller than that of control Pomp-VG-injected embryos at 60 and 84 hpf (Dunnett's test; $p<0.001$ and $p=0.001$, respectively) (Fig. $4 F, G, K$ ). Consistently, the VAMP2-EGFP punctate area in the axon terminals of Pomp-VG-VP16CREB-injected embryos were significantly 
larger than those of control Pomp-VGinjected embryos at $36 \mathrm{hpf}$ (Dunnett's test; $p=0.004$ ) (Fig. $4 H, K)$. The terminal reach values measured using tau-EGFP as a marker at 60 and $84 \mathrm{hpf}$ were comparable among olfactory sensory neurons expressing A-CREB (60 hpf, $80.1 \pm 2.5 \mu \mathrm{m}, n=$ 49, 12 embryos; 84 hpf, $83.9 \pm 2.5 \mu \mathrm{m}, n=$ 55, 10 embryos), VP16-CREB (60 hpf, $79.0 \pm 1.6 \mu \mathrm{m}, n=45,17$ embryos; $84 \mathrm{hpf}$, $86.1 \pm 2.1 \mu \mathrm{m}, n=31,16$ embryos), or tau-EGFP alone $(60 \mathrm{hpf}, 80.8 \pm 2.0 \mu \mathrm{m}$, $n=48,14$ embryos; $84 \mathrm{hpf}, 82.0 \pm 2.1 \mu \mathrm{m}$, $n=51,13$ embryos). These results suggest that CREB regulates the VAMP2-EGFP punctum formation in the axon terminals of olfactory sensory neurons.

To monitor the activation of endogenous CREB in the olfactory placode, we injected a reporter vector carrying the CRE promoter-driven destabilized variant of EYFP (d2EYFP) linked to the EF1 $\alpha$ promoter-driven destabilized variant of ECFP (d2ECFP) (supplemental Fig. 1A, available at www.jneurosci.org as supplemental material). The level of endogenous CREB-mediated transcription in the olfactory placode, measured as fluorescent intensity of d2EYFP, was low at 24 and $36 \mathrm{hpf}$ but significantly increased at $60 \mathrm{hpf}$ and remained high at 72 and $84 \mathrm{hpf}$, whereas d2ECFP signals as an internal control of the expression vector decreased gradually during development (supplemental Fig. $1 B-D$, available at www. jneurosci.org as supplemental material). These results suggest the activation of endogenous CREB signaling during axon terminal differentiation of olfactory sensory neurons.

\section{Axon terminal morphology of olfactory sensory neurons during synapse formation}

Differentiation of an axonal growth cone into a nerve terminal is often accompanied by marked structural changes (Kullberg et al., 1977; Hamori and Somogyi, 1983; Dent et al., 1999). We next analyzed the morphology of axon terminals of olfactory neurons during synaptogenesis using GAP43-EGFP as a marker, because GAP43 is enriched in the plasma membrane of axonal growth cones (Meiri et al., 1986; Skene, 1989), and GAP43-EGFP fusion protein was targeted to the growth cone (Nakata et al., 1998). We injected the omp promoter-driven GAP43-EGFP construct (Fig. $5 A$ ) and visualized the morphology of axon terminals of olfactory sensory neurons. Filopodia-like protrusions were more apparent, and the framework was more complex in axon terminals at 36 and $60 \mathrm{hpf}$ than those at $84 \mathrm{hpf}$ (Fig. 5B-D).

To quantify the morphological change of the axon terminals, we measured the area, perimeter, and complexity values of axon terminals labeled with GAP43-EGFP at 36, 60, and $84 \mathrm{hpf}$. These values were high at 36 and $60 \mathrm{hpf}$ but significantly decreased at 84 hpf (one-way ANOVA; area, $p=0.0033$; perimeter, $p=0.0046$; complexity, $p=0.0068$ ) (Fig. $5 K-M$ ). The area, perimeter, and complexity values of axon terminals visualized with cytosolic EGFP-actin fusion protein were comparable with those with GAP43-EGFP at 36, 60, and $84 \mathrm{hpf}$ (two-way ANOVA; expression vector effect, $p=0.42$ for axon terminal area, $p=0.82$ for axon terminal perimeter, and $p=0.68$ for axon terminal complexity). These results showed that the morphology of axon ter- minals of olfactory neurons was remodeled from large and complex shapes into small and simple shapes during development. The diameter of glomeruli visualized by BODIPY labeling (Dynes and Ngai, 1998) was at most $10.7 \pm 0.4 \mu \mathrm{m}(n=25$ in lateral glomeruli of five embryos) at $84 \mathrm{hpf}$. However, the stretch of axon terminals at $60 \mathrm{hpf}$ was $17.8 \pm 0.9 \mu \mathrm{m}(n=43 ; 28$ embryos $)$. The value decreased to $11.0 \pm 0.6 \mu \mathrm{m}(n=40 ; 26$ embryos $)$ by $84 \mathrm{hpf}$, which was comparable with the diameter of glomeruli. Thus, the axon terminal remodeling visualized by GAP43-EGFP is also a good indicator of the axon terminal maturation.

\section{Constitutively active calcineurin stimulates morphological remodeling of axon terminals}

We then examined the effects of $\mathrm{caCN}$ and $\mathrm{PKA}^{\star}$ on the remodeling of the axon terminal morphology of olfactory sensory neurons in the course of synaptogenesis. The omp promoter-driven $\mathrm{caCN}$ and $\mathrm{PKA}^{*}$ genes were fused to the omp promoter-driven GAP43-EGFP fusion protein gene to yield Pomp-GG-caCN and Pomp-GG-PKA* double-cassette expression vectors, respectively (Fig. 5A). We compared the morphology of growing axon terminals among embryos injected with Pomp-GG, Pomp-GGcaCN, and Pomp-GG-PKA* at 36, 60, and $84 \mathrm{hpf}$. The axon terminal morphology of olfactory neurons expressing caCN at 60 hpf (Fig. $5 F$ ) became as simple as those of control axons at $84 \mathrm{hpf}$ (Fig. 5D). On the other hand, the axon terminal morphology of olfactory neurons expressing $\mathrm{PKA}^{*}$ at 36 and $60 \mathrm{hpf}$ was more complex than that of olfactory neurons expressing GAP43-EGFP alone (Fig. $5 B, C, H, I$ ). At $84 \mathrm{hpf}$, axon terminals became simple shapes with few filopodia-like protrusions in embryos injected with Pomp-GG, Pomp-GG-caCN, and Pomp-GG-PKA*.

To quantify the effects of $\mathrm{caCN}$ and $\mathrm{PKA}^{\star}$ on the axon terminal remodeling, we measured the area, perimeter, and complexity values of axon terminals labeled with GAP43-EGFP at 36, 60, and 84 hpf. There were significant differences in these parameters among Pomp-GG-, Pomp-GG-caCN-, and Pomp-GG-PKA*injected embryos (two-way ANOVA; axon terminal area, expres- 

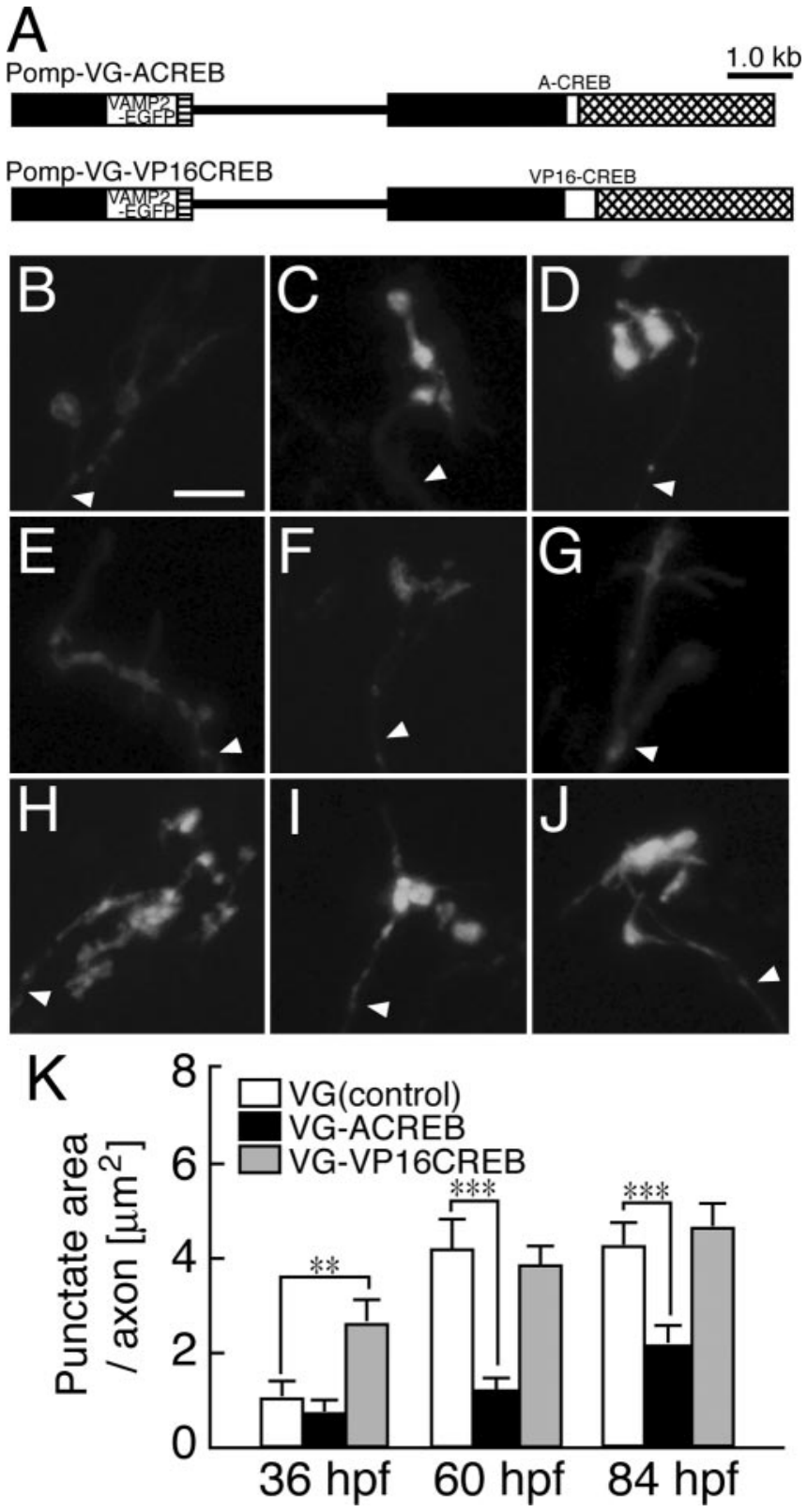

Figure 4. Effects of dominant-negative CREB and constitutively active CREB on the development of VAMP2-EGFP puncta in axon terminals of olfactory sensory neurons. $A, 0 \mathrm{mp}$ promoterdriven expression vectors for A-CREB and VAMP2-EGFP (top) and for VP16-CREB and VAMP2EGFP (bottom) in olfactory sensory neurons. Black boxes, The omp promoter; cross-hatched boxes, the $3^{\prime}$ downstream sequence of the omp gene; hatched boxes, SV40 polyadenylation signal sequence; lines, pBluescript II SK+. $\boldsymbol{B}-\boldsymbol{J}$, Representative VAMP2-EGFP signals in axon terminals of olfactory sensory neurons in embryos injected with Pomp-VG (B-D), Pomp-VGACREB (E-G), or Pomp-VG-VP16CREB (H-J) at $36 \mathrm{hpf}(\boldsymbol{B}, \boldsymbol{E}, \boldsymbol{H}), 60 \mathrm{hpf}(\boldsymbol{C}, \boldsymbol{F}, \boldsymbol{I})$, and $84 \mathrm{hpf}(\boldsymbol{D}$, $\boldsymbol{G}, \boldsymbol{J})$. Arrowheads point to axonal shafts. Scale bar, $5 \mu \mathrm{m}$. $\boldsymbol{K}$, The area of VAMP2-EGFP puncta in axon terminals of olfactory sensory neurons in zebrafish embryos injected with Pomp-VG (open bars), Pomp-VG-ACREB (black bars), and Pomp-VG-VP16CREB (gray bars) expression vectors at 36,60 , and $84 \mathrm{hpf}$. Pomp-VG, $n=32,35$, and 37 at 36, 60, and 84 hpf, respectively, 22-26 embryos; Pomp-VG-ACREB, $n=35,41$, and 36 at 36, 60, and 84 hpf, respectively, 18 19 embryos; Pomp-VG-VP16CREB, $n=33,33$, and 34 at 36, 60, and $84 \mathrm{hpf}$, respectively, $22-27$ embryos. All values represent mean \pm SEM. ${ }^{* *} p<0.01 ;{ }^{* * *} p<0.001$.

sion vector effect, $p=0.0002$, age $\times$ expression vector interaction, $p=0.028$; axon terminal perimeter, expression vector effect, $p=0.0001$, age $\times$ expression vector interaction, $p=0.008$; axon terminal complexity, expression vector effect, $p=0.0003$, age $\times$ expression vector interaction, $p=0.002)($ Fig. $5 B-M)$. The perimeter and complexity values were significantly smaller in Pomp-GG-caCN-injected embryos than in control embryos at 60 hpf (Dunnett's test; $p=0.008$ and 0.002 , respectively) (Fig. $5 L, M)$. Furthermore, the area, perimeter, and complexity values of Pomp-GG-caCN-injected embryos at $60 \mathrm{hpf}$ were comparable with those of control embryos at $84 \mathrm{hpf}$. There were no significant differences in the area, perimeter, and complexity values between Pomp-GG- and Pomp-GG-caCN-injected embryos at $84 \mathrm{hpf}$. These results suggest that the stimulation of calcineurin promoted the remodeling of axon terminal morphology of olfactory sensory neurons.

The perimeter and complexity values of axon terminals of olfactory sensory neurons in embryos injected with Pomp-GG$\mathrm{PKA}^{*}$ vector were significantly larger than those in embryos injected with control Pomp-GG vector at $36 \mathrm{hpf}$ (Dunnett's test; $p=0.044$ and 0.026 , respectively) (Fig. $5 L, M$ ). This suggests that PKA signaling may be involved in the regulation of growth cone morphology at the axon pathfinding stage. The area, perimeter, and complexity values of axon terminals of olfactory sensory neurons at $60 \mathrm{hpf}$ were also significantly larger in Pomp-GG$\mathrm{PKA}^{*}$-injected embryos than in control GG-injected embryos (Dunnett's test; $p=0.001,0.003$, and 0.011, respectively) (Fig. $5 K-M)$. At $84 \mathrm{hpf}$, the area, perimeter, and complexity values were comparable between Pomp-GG-PKA* - and Pomp-GGinjected embryos (Fig. $5 K-M$ ). The complexity value of growth cones expressing dominant-negative PKA $(112.7 \pm 9.8 ; n=40$; 29 embryos) was significantly smaller than that of control growth cones expressing GAP43-EGFP alone (145.6 $\pm 11.2 ; n=33 ; 27$ embryos) at $36 \mathrm{hpf}(t$ test; $p=0.03)$. However, the expression of dnPKA exerted little effect on the complexity at 60 and at $84 \mathrm{hpf}$ (data not shown). These results suggest that PKA signaling regulates the growth cone morphology at the axon pathfinding stage but is not involved in the control of axon terminal remodeling during synaptogenesis. Expression of A-CREB or VP16-CREB exerted no significant effects on the morphological remodeling (two-way ANOVA; expression vector effect, $p=0.46,0.62$, and 0.68 for axon terminal area, perimeter, and complexity, respectively; age $\times$ expression vector interaction, $p=0.88,0.85$, and 0.84 for axon terminal area, perimeter, and complexity, respectively).

\section{Pharmacological suppression of calcineurin prevents axon} terminals from morphological change

To further examine the physiological significance of calcineurin signaling in the morphological change of axon terminals during the course of development, we tested the effects of cyclosporine $\mathrm{A}$, an immunosuppressive drug that inhibits calcineurin through cyclophilin in wide variety of species (Liu et al., 1991; Kunz and Hall, 1993). Zebrafish embryos injected with Pomp-GG vector were soaked in a suspension of cyclosporine A from 30 to $84 \mathrm{hpf}$. The cyclosporine A treatment caused no apparent effects on the gross morphology of embryos. The labeled axon terminals of olfactory neurons were imaged by a confocal microscope at 60 and $84 \mathrm{hpf}$. The axon terminals of olfactory sensory neurons in mock-treated embryos were remodeled to simple shapes from 60 to $84 \mathrm{hpf}$ (Fig. 6A,B), as those in untreated embryos (Fig. 5C,D). Accordingly, the area, perimeter, and complexity values significantly decreased from 60 to $84 \mathrm{hpf}$ in mock-treated embryos $(t$ test; $p=0.012,0.0015$, and 0.00073 , respectively). The treatment with cyclosporine $\mathrm{A}$, however, suppressed the remodeling of axon terminals from complex to simple shapes as indicated by very complex shapes of axon terminals with many filopodia even at $84 \mathrm{hpf}$ (Fig. 6C,D). Consistently, the area, perimeter, and com- 
plexity values were comparable between 60 and $84 \mathrm{hpf}$ in cyclosporine A-treated embryos ( $t$ test; $p=0.35,0.64$, and 0.098 , respectively). The olfactory sensory neurons of cyclosporine A-treated embryos showed a significantly higher complexity value in axon terminal morphology at 60 hpf than those of mock-treated embryos ( $t$ test; $p=0.044$ ) (Fig. 6G). Furthermore, at $84 \mathrm{hpf}$, the area, perimeter, and complexity values were all significantly larger in cyclosporine A-treated embryos than in mock-treated embryos ( $t$ test; $p=0.026$, $1.2 \times 10^{-5}$, and $1.1 \times 10^{-6}$, respectively) (Fig. $6 E-G$ ). The terminal reach values of cyclosporine A-treated embryos at $60 \mathrm{hpf}$ (79.5 $\pm 2.8 \mu \mathrm{m} ; n=24 ; 11$ embryos) and $84 \mathrm{hpf}(87.9 \pm 5.0 \mu \mathrm{m} ; n=14$; five embryos) were comparable with those of mock-treated embryos at $60 \mathrm{hpf}(78.0 \pm$ $2.0 \mu \mathrm{m} ; n=28$; nine embryos; $t$ test; $p=$ $0.65)$ and $84 \mathrm{hpf}(83.7 \pm 2.0 \mu \mathrm{m} ; n=39$; nine embryos; $t$ test; $p=0.45)$, respectively. Moreover, there were no significant differences in VAMP2-EGFP punctate area between cyclosporine A- and mocktreated embryos at $84 \mathrm{hpf}$ (mock treatment, $6.53 \pm 0.42 \mu \mathrm{m}^{2}, n=36,22 \mathrm{em}-$ bryos; cyclosporine A treatment, $5.64 \pm$ $0.43 \mu \mathrm{m}^{2}, n=41,23$ embryos; $t$ test; $p=$ 0.15). Thus, the treatment of cyclosporine A from 30 to $84 \mathrm{hpf}$ appeared to exert little effect on axon projection and synaptic vesicle accumulation. These results suggest that the suppression of calcineurin by cyclosporine A prevented the remodeling of axon terminal morphology from large and complex shapes to small and simple shapes between 60 and $84 \mathrm{hpf}$. These results fur-

ther support the idea that calcineurin regulates the morphological maturation of axon terminals of olfactory sensory neurons.

\section{NFAT activation is required for the morphological change of axon terminals}

One of major calcineurin target proteins is the transcription factor NFAT, which is expressed at high levels in the axon terminals of murine olfactory sensory neurons (Jain et al., 1993; Ho et al., 1994). We thus examined the morphological remodeling of axon terminals in response to the suppression of NFAT activation by calcineurin. A potent immunosuppressive VIVIT peptide is derived from the calcineurin docking motif of mammalian NFAT (PxIxIT; $x$, any amino acid) and GFP-VIVIT fusion protein selectively inhibits NFAT activation without disrupting other calcineurin-dependent pathways (Aramburu et al., 1999). GSTVIVIT fusion protein also suppresses NFAT activation (Namiki et al., 2003). Because zebrafish NFATs also have conserved PxIxIT motif (http://www.ensembl.org/Danio_rerio), we constructed GST-VIVIT and GST-scrambled VIVIT-CP fusion genes and placed them in the effector-reporter cassette to obtain Pomp-GG-GST-VIVIT and Pomp-GG-GST-CP, respectively (Fig. 7A).

The axon terminals of olfactory sensory neurons in control embryos injected with Pomp-GG-GST-CP were remodeled to simple shapes during development (one-way ANOVA; axon terminal area, $p=7.7 \times 10^{-6}$; axon terminal perimeter, $p=7.4 \times$ $10^{-6}$; axon terminal complexity, $p=4.1 \times 10^{-5}$ ) (Fig. $7 \mathrm{~B}, \mathrm{C}, \mathrm{F}-\mathrm{H}$ ) as those in Pomp-GG-injected embryos (Fig. $5 C, D$ ). In contrast, the axon terminals of olfactory sensory neurons in embryos injected with Pomp-GG-GST-VIVIT showed no morphological changes during development (one-way ANOVA; axon terminal area, $p=0.2$; axon terminal perimeter, $p=0.7$; axon terminal complexity, $p=0.95$ ) (Fig. $7 D-H$ ). There were significant differences in developmental changes of the axon terminal area, perimeter, and complexity between Pomp-GG-GSTVIVIT- and Pomp-GG-GST-CP-injected embryos (two-way ANOVA; axon terminal area, expression vector effect, $p=5.9 \times$ $10^{-4}$, age $\times$ expression vector interaction, $p=0.013$; axon terminal perimeter, expression vector effect, $p=1.7 \times 10^{-4}$, age $\times$ expression vector interaction, $p=0.013$; axon terminal complexity, expression vector effect, $p=2.4 \times 10^{-4}$, age $\times$ expression vector interaction, $p=0.033$ ) (Fig. $7 B-H$ ). The area, perimeter, and complexity values were significantly larger in Pomp-GGGST-VIVIT-injected embryos than in control Pomp-GG-GST$\mathrm{CP}$-injected embryos at $84 \mathrm{hpf}\left(t\right.$ test; $p=1.7 \times 10^{-5}, 6.4 \times$ $10^{-6}$, and $9.7 \times 10^{-6}$, respectively) (Fig. $\left.7 F-H\right)$. The terminal reach values measured using tau-EGFP as a marker at 60 and 84 hpf were comparable between olfactory sensory neurons express- 

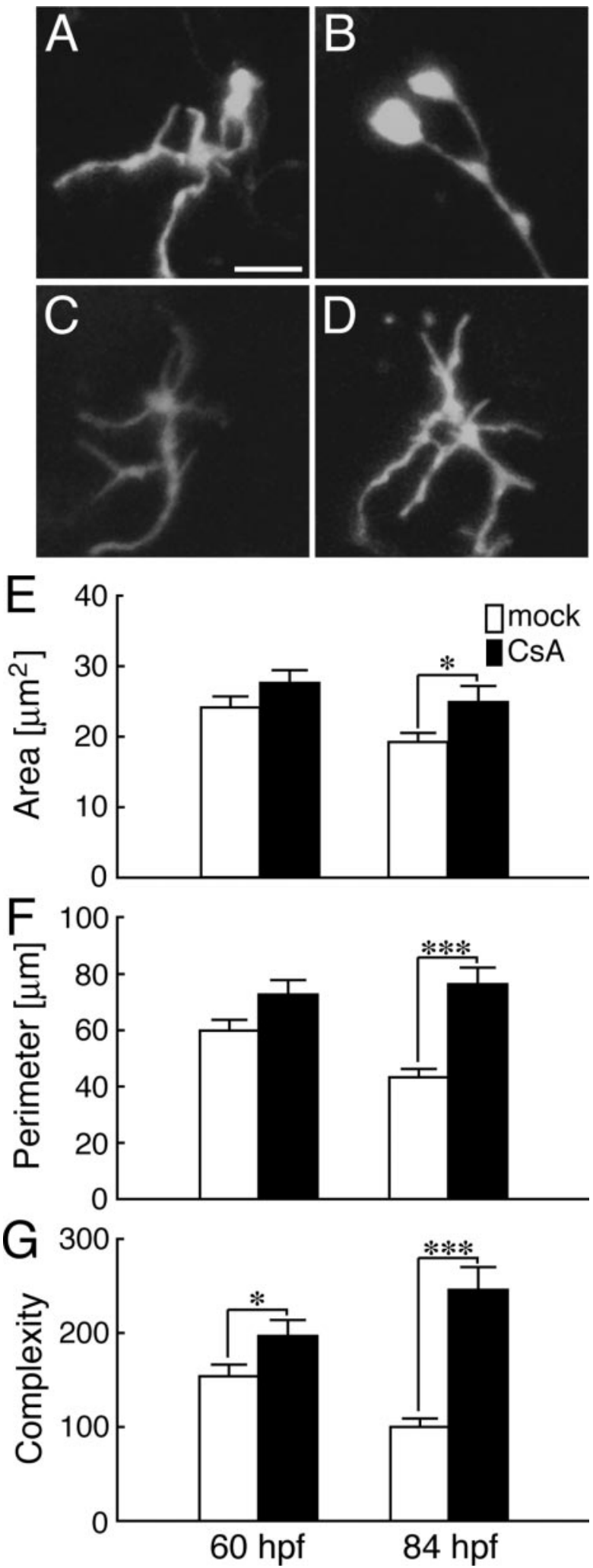

Figure 6. Effects of cyclosporine A treatment on the axon terminal morphology of olfactory sensory neurons. $\boldsymbol{A}-\boldsymbol{D}$, Representative images of the axon terminal morphology of olfactory sensory neurons in mock-treated $(\boldsymbol{A}, \boldsymbol{B})$ and cyclosporine $A$-treated $(\boldsymbol{C}, \boldsymbol{D})$ embryos injected with Pomp-GG vector at $60 \mathrm{hpf}(\boldsymbol{A}, \boldsymbol{C})$ and $84 \mathrm{hpf}(\boldsymbol{B}, \boldsymbol{D})$. Scale bar, $5 \mu \mathrm{m}$. $\boldsymbol{E}-\boldsymbol{G}$, The area $(\boldsymbol{E})$, perimeter $(\boldsymbol{F})$, and complexity $(\boldsymbol{G})$ values of axon terminals of olfactory sensory neurons in mock-treated and cyclosporine A-treated (CsA) embryos injected with Pomp-GG vector at 60 and 84 hpf. Mock treatment, $n=43$ and 42 for 28 and 26 embryos at 60 and $84 \mathrm{hpf}$, respectively; cyclosporine $A$ treatment, $n=30$ and 30 for 18 and 19 embryos at 60 and 84 hpf, respectively. All values represent mean \pm SEM. ${ }^{*} p<0.05 ;{ }^{* * *} p<0.001$. ing GST-VIVIT (60 hpf, $82.2 \pm 1.8 \mu \mathrm{m}, n=47,11$ embryos; 84 hpf, $90.9 \pm 2.4 \mu \mathrm{m}, n=44,11$ embryos) and GST-CP (60 hpf, $82.5 \pm 2.1 \mu \mathrm{m}, n=47,13$ embryos; $84 \mathrm{hpf}, 86.1 \pm 2.9 \mu \mathrm{m}, n=$ 42, 10 embryos). Moreover, expression of GST-VIVIT in the olfactory sensory neurons exerted no significant effects on VAMP2-EGFP punctate area at $84 \mathrm{hpf}$ (control, $6.53 \pm 0.42$ $\mu \mathrm{m}^{2}, n=36,22$ embryos; GST-VIVIT expression, $5.99 \pm 0.6$ $\mu \mathrm{m}^{2}, n=38,23$ embryos; $t$ test; $p=0.46$ ). These results suggest that the activation of NFAT by calcineurin is essential for the morphological remodeling of olfactory sensory neuron axon terminals.

\section{Discussion}

Synaptic vesicle accumulation and morphological change are the hallmarks of axon terminal maturation during synapse formation. Here, we show that the two events are regulated by distinct signaling systems.

PKA-CREB signaling regulates synaptic vesicle accumulation at axon terminals

VAMP2-EGFP is a well characterized marker of synaptic vesicles (Miesenbock et al., 1998; Nonet, 1999; Ahmari et al., 2000). We found that the area of VAMP2-EGFP punctum in olfactory sensory neurons markedly increased between 36 and 84 hpf. Punctate VAMP2-ECFP signals in the axon terminals of olfactory sensory neurons merged well with signals of Bassoon-EYFP and endogenous syntaxin, indicating their localization near the active zone of presynaptic nerve terminals (tom Dieck et al., 1998; Dresbach et al., 2003). The expression of constitutively active calcineurin exerted little effect on the development of VAMP2EGFP puncta. In contrast, we found that constitutively active PKA increased the area of VAMP2-EGFP puncta at $36 \mathrm{hpf}$ during axon pathfinding stage. Consistently, dominant-negative PKA suppressed the VAMP2-EGFP punctum formation at 60 and 84 hpf during synaptogenesis. Our previous studies showed that $\mathrm{PKA}^{*}$ slightly increased the terminal reach of olfactory sensory neurons at $50 \mathrm{hpf}$ when axons stopped extension, whereas the expression of dominant-negative PKA exerted little effect on the terminal reach (Yoshida et al., 2002). If PKA* would induce overshooting of axon terminals, synaptic vesicle accumulation associated with synaptogenesis could be delayed. However, PKA* stimulated the VAMP2-EGFP punctum formation despite the slight disturbing effects on the target projection. Thus, the opposite effects of constitutively active and dominant-negative PKAs on the VAMP2-EGFP punctum formation suggest that PKA activity is an important regulator of synaptic vesicle accumulation in axon terminals.

We also found that the expression of constitutively active CREB increased the area of VAMP2-EGFP puncta at $36 \mathrm{hpf}$, and the expression of dominant-negative CREB suppressed the VAMP2-EGFP punctum formation at 60 and 84 hpf during synaptogenesis without affecting axon projection. The consistent effects of the activation and suppression of PKA and CREB on VAMP2-EGFP punctum formation suggest that PKA regulates synaptic vesicle accumulation in axon terminals through activation of CREB. PKA substrates in the axon terminal may also mediate PKA regulation of synaptic vesicle accumulation in concert with CREB signaling in the nucleus. In fact, various synaptic vesicle and active zone proteins including synapsins, soluble NSF attachment protein ( $\alpha \mathrm{SNAP})$, synaptosome-associated protein of $25 \mathrm{kDa}$, and RIM1 $\alpha$ are the substrates for PKA (Südhof et al., 1989; Hirling and Scheller, 1996; Risinger and Bennett, 1999; Lonart et al., 2003). Synapsins interact with both cytoskeletal 
elements and synaptic vesicles in a phosphorylation-dependent manner and play a role in vesicle clustering in the reserve pool (Schiebler et al., 1986; Benfenati et al., 1992; Pieribone et al., 1995; Takei et al., 1995; Hosaka et al., 1999). In addition, phosphorylation by PKA of kinesin, one of anterograde motor proteins that transport synaptic vesicles to the axon terminal, reduces the ability of kinesin to bind synaptic vesicles (Hirokawa et al., 1991; SatoYoshitake et al., 1992).

Cumulative evidence suggests that PKA-CREB signaling regulates plastic changes in presynaptic function. For example, long-term facilitation of synaptic transmission between cultured sensorymotor neurons of Aplysia is repressed by injection of oligonucleotides containing CRE-binding sites into the nucleus of presynaptic sensory neurons (Dash et al., 1990). In addition, presynaptic cAMP mediates long-term potentiation at the mossy fiber synapses in the rat hippocampal CA3 region (Huang et al., 1994). The expression of dCREB2-b, a CREB repressor, in Drosophila dunce mutants suppresses the increase in quantal content at the neuromuscular junction, but the expression in wild-type flies exerts no effect on the quantal content, suggesting that CREB is required for cAMP-dependent presynaptic enhancement but not for synaptic maturation during development (Davis et al., 1996). However, our results show that the expression of dnPKA or A-CREB suppresses VAMP2-EGFP punctum formation in axon terminals of olfactory sensory neurons during synapse formation. Thus, the present investigation sheds light on a novel role of PKA-CREB signaling in maturation of presynaptic terminals during development.

\section{Calcineurin-NFAT signaling regulates axon terminal remodeling}

By labeling with GAP43-EGFP, we found that axon terminals of olfactory sensory neurons drastically changed their morphology during development from complex shapes with many filopodia at $60 \mathrm{hpf}$ to simple shapes without filopodia at $84 \mathrm{hpf}$. Accordingly, the stretches of the axon terminals decreased from 60 to $84 \mathrm{hpf}$. The stretch at $84 \mathrm{hpf}$ was comparable with the diameter of glomeruli visualized by BODIPY labeling (Dynes and Ngai, 1998). Because synaptogenesis started at $\sim 50 \mathrm{hpf}$, the decrease in the stretch of axon terminals from 60 to $84 \mathrm{hpf}$ may reflect the refinement and maturation of axon terminals. The glomerulus structures became apparent by 84 but not at 48 hpf (Dynes and Ngai, 1998). Thus, the axon terminal remodeling probably followed the initial stage of synapse formation.

The expression of constitutively active calcineurin in olfactory sensory neurons reduced the perimeter and complexity values of axon terminals at $60 \mathrm{hpf}$ to those in control embryos at $84 \mathrm{hpf}$. On the other hand, the perimeter and complexity values remained unaltered at 36 and $84 \mathrm{hpf}$. Because the expression of constitutively active calcineurin hardly affected the terminal reach value of olfactory neuron axons, it is unlikely that its effect on the axon terminal morphology at $60 \mathrm{hpf}$ is because of alterations in the axon extension and target selection. Suppression of endogenous calcineurin with cyclosporine A inhibited the reduction in the perimeter and complexity values of axon terminals during development from 60 to $84 \mathrm{hpf}$. The opposite effects of constitutively active calcineurin and cyclosporine A suggest that calcineurin activity is required for the axon terminal remodeling of olfactory sensory neurons in vivo. The expression of GST-fused VIVIT peptide that specifically blocks the activation of nuclear transcription factors of the NFAT family by calcineurin suppressed the remodeling of axon terminals between 60 and $84 \mathrm{hpf}$. These results suggest that calcineurin regulates the remodeling of axon terminals of olfactory sensory neurons through NFAT-mediated signaling. Because NFAT acts as a transcription factor (Graef et al., 2001), the remodeling of axon terminals of olfactory sensory neurons may require gene expression. Besides nuclear transcription, some molecules in the axon terminal may also mediate calcineurin regulation of axon terminal remodeling in concert with NFAT signaling. In fact, GAP43 enriched in growth cones is a substrate for calcineurin (Liu and Storm, 1989), and dephosphorylated GAP43 inhibits actin filament polymerization (He et al., 1997). Furthermore, Tau and microtubule-associated protein $1 \mathrm{~B}$ (MAP1B), which regulate the microtubule organization, are also dephoshorylated by calcineurin (Ulloa et al., 1993; Billingsley and Kincaid, 1997). Interestingly, mutation of the Drosophila MAP1B 
homolog gene futsch disturbed synaptic microtubule organization and increased the size of synaptic bouton (Hummel et al., 2000; Roos et al., 2000).

Calcineurin stimulates or inhibits neurite outgrowth of cultured neurons (Lyons et al., 1994; Chang et al., 1995; Lautermilch and Spitzer, 2000). Mutant mice lacking NFATc2, c3, and c4 have defects in peripheral axon projections from the dorsal root ganglion and trigeminal ganglion and in projection of spinal commissural axons (Graef et al., 2003). In our study, however, inhibition of calcineurin and NFAT did not affect the axon extension and projection of olfactory neurons as evaluated by terminal reach values. Because the axon extension of zebrafish olfactory neurons start by $22 \mathrm{hpf}$ (Yoshida et al., 2002), cyclosporine A treatment after $30 \mathrm{hpf}$ and omp-promoter driven GST-VIVIT peptide expression may be too late to affect the initial stage of axon extension. The present investigation highlights a key regulatory role of calcineurin-NFAT signaling in the morphological change of axon terminals during synaptogenesis.

The expression of constitutively active PKA increased the area, perimeter, and complexity values of axon terminals of olfactory neurons at 36 and $60 \mathrm{hpf}$. These values of olfactory sensory neurons at $84 \mathrm{hpf}$, however, decreased to levels comparable with those in control axons at $84 \mathrm{hpf}$. The dominant-negative PKA decreased the complexity at $36 \mathrm{hpf}$ but exerted little effect at 60 and 84 hpf. It is likely that PKA regulates the growth cone morphology in the axon pathfinding stage but is not involved in the remodeling of axon terminal morphology at the synaptogenesis stage. The morphological changes of axon terminals at 36 and 60 hpf induced by PKA modulation may be ascribed to the disturbance of axon pathfinding, because PKA activity regulates growth cone responsiveness to guidance molecules (Song and Poo, 1999; Yoshida et al., 2002).

\section{Activation of calcineurin signaling and PKA signaling should be coordinated in axon terminals}

Our results provide evidence that PKA-CREB signaling is important for the synaptic vesicle accumulation in axon terminals, and calcineurin-NFAT signaling regulates the morphological remodeling of axon terminals of zebrafish olfactory sensory neurons during synapse formation (supplemental Fig. 2, available at www.jneurosci.org as supplemental material). Thus, two distinct signaling systems control two representative events of axon terminal maturation independently. Requirement of CREB and NFAT activation indicates the importance of gene transcription for the presynaptic differentiation. To orchestrate the presynaptic differentiation, however, there should be a mechanism that coordinates the two signaling systems. $\mathrm{Ca}^{2+} /$ calmodulin required for the activation of calcineurin (Klee et al., 1979) can also activate adenylyl cyclases of type 1, 3, and 8 (Mons et al., 1999). It is known that type 3 adenylyl cyclase is enriched in mouse olfactory sensory neurons (Bakalyar and Reed, 1990). Thus, $\mathrm{Ca}^{2+} /$ calmodulin is a candidate molecule that coordinates the calcineurinNFAT and PKA-CREB signaling in axon terminals (supplemental Fig. 2, available at www.jneurosci.org as supplemental material). Another candidates are target-derived factors such as WNT-7a and FGF22, which induce presynaptic differentiation (Hall et al., 2000; Umemori et al., 2004). Although intracellular signaling mediated by these molecules are not fully elucidated, CREB and NFAT may be master downstream targets of these signals. In concert with these transcriptional factors, PKAphosphorylated and calcineurin-dephosphorylated molecules localized in the axon terminal would also mediate synaptic vesicle accumulation and axon terminal remodeling. In addition, such molecules may act as synaptic tags (Frey and Morris, 1997) for recruiting newly synthesized proteins to $\mathrm{Ca}^{2+} /$ calmodulinactivated terminals. The neuron- and stage-specific expression of both effector and reporter molecules in combination with in vivo observation of a single neuron in living zebrafish embryos will provide a useful tool for the elucidation of molecular mechanisms underlying synapse formation and synapse dynamics.

\section{References}

Ahmari SE, Buchanan J, Smith SJ (2000) Assembly of presynaptic active zones from cytoplasmic transport packets. Nat Neurosci 3:445-451.

Ahn S, Olive M, Aggarwal S, Krylov D, Ginty DD, Vinson C (1998) A dominant-negative inhibitor of CREB reveals that it is a general mediator of stimulus-dependent transcription of c-fos. Mol Cell Biol 18:967-977.

Aramburu J, Yaffe MB, Lopez-Rodriguez C, Cantley LC, Hogan PG, Rao A (1999) Affinity-driven peptide selection of an NFAT inhibitor more selective than cyclosporin A. Science 285:2129-2133.

Bakalyar HA, Reed RR (1990) Identification of a specialized adenylyl cyclase that may mediate odorant detection. Science 250:1403-1406.

Benfenati F, Valtorta F, Chieregatti E, Greengard P (1992) Interaction of free and synaptic vesicle-bound synapsin I with F-actin. Neuron 8:377-386.

Biederer T, Sara Y, Mozhayeva M, Atasoy D, Liu X, Kavalali E, Südhof TC (2002) SynCAM, a synaptic adhesion molecule that drives synapse assembly. Science 297:1525-1531.

Billingsley ML, Kincaid RL (1997) Regulated phosphorylation and dephosphorylation of tau protein: effects on microtubule interaction, intracellular trafficking and neurodegeneration. Biochem J 323:577-591.

Chang HY, Takei K, Sydor AM, Born T, Rusnak F, Jay DG (1995) Asymmetric retraction of growth cone filopodia following focal inactivation of calcineurin. Nature 376:686-690.

Clegg CH, Correll LA, Cadd GG, McKnight GS (1987) Inhibition of intracellular cAMP-dependent protein kinase using mutant genes of the regulatory type I subunit. J Biol Chem 262:13111-13119.

Clipstone NA, Crabtree GR (1992) Identification of calcineurin as a key signalling enzyme in T-lymphocyte activation. Nature 357:695-697.

Dash PK, Hochner B, Kandel ER (1990) Injection of the cAMP-responsive element into the nucleus of Aplysia sensory neurons blocks long-term facilitation. Nature 345:718-721.

Davis GW, Schuster CM, Goodman CS (1996) Genetic dissection of structural and functional components of synaptic plasticity. III. CREB is necessary for presynaptic functional plasticity. Neuron 17:669-679.

Dean C, Scholl FG, Choih J, DeMaria S, Berger J, Isacoff E, Scheiffele P (2003) Neurexin mediates the assembly of presynaptic terminals. Nat Neurosci 6:708-716.

Dent EW, Callaway JL, Szebenyi G, Baas PW, Kalil K (1999) Reorganization and movement of microtubules in axonal growth cones and developing interstitial branches. J Neurosci 19:8894-8908.

Dresbach T, Qualmann B, Kessels MM, Garner CC, Gundelfinger ED (2001) The presynaptic cytomatrix of brain synapses. Cell Mol Life Sci 58:94-116.

Dresbach T, Hempelmann A, Spilker C, tom Dieck S, Altrock WD, Zuschratter W, Garner CC, Gundelfinger ED (2003) Functional regions of the presynaptic cytomatrix protein bassoon: significance for synaptic targeting and cytomatrix anchoring. Mol Cell Neurosci 23:279-291.

Dynes JL, Ngai J (1998) Pathfinding of olfactory neuron axons to stereotyped glomerular targets revealed by dynamic imaging in living zebrafish embryos. Neuron 20:1081-1091.

Elferink LA, Scheller RH (1993) Synaptic vesicle proteins and regulated exocytosis. J Cell Sci Suppl 17:75-79.

Frey U, Morris RG (1997) Synaptic tagging and long-term potentiation. Nature 385:533-536.

Friedrich RW, Korsching SI (1997) Combinatorial and chemotopic odorant coding in the zebrafish olfactory bulb visualized by optical imaging. Neuron 18:737-752.

Garner CC, Kindler S, Gundelfinger ED (2000) Molecular determinants of presynaptic active zones. Curr Opin Neurobiol 10:321-327.

Graef IA, Chen F, Crabtree GR (2001) NFAT signaling in vertebrate development. Curr Opin Genet Dev 11:505-512.

Graef IA, Wang F, Charron F, Chen L, Neilson J, Tessier-Lavigne M, Crabtree GR (2003) Neurotrophins and netrins require calcineurin/NFAT signaling to stimulate outgrowth of embryonic axons. Cell 113:657-670. 
Hall AC, Lucas FR, Salinas PC (2000) Axonal remodeling and synaptic differentiation in the cerebellum is regulated by WNT-7a signaling. Cell 100:525-535.

Hammerschmidt M, Bitgood MJ, McMahon AP (1996) Protein kinase A is a common negative regulator of Hedgehog signaling in the vertebrate embryo. Genes Dev 10:647-658.

Hamori J, Somogyi J (1983) Differentiation of cerebellar mossy fiber synapses in the rat: a quantitative electron microscope study. J Comp Neurol 220:365-377.

He Q, Dent EW, Meiri KF (1997) Modulation of actin filament behavior by GAP-43 (neuromodulin) is dependent on the phosphorylation status of serine 41, the protein kinase C site. J Neurosci 17:3515-3524.

Hirling H, Scheller RH (1996) Phosphorylation of synaptic vesicle proteins: modulation of the $\alpha$ SNAP interaction with the core complex. Proc Natl Acad Sci USA 93:11945-11949.

Hirokawa N, Sato-Yoshitake R, Kobayashi N, Pfister KK, Bloom GS, Brady ST (1991) Kinesin associates with anterogradely transported membranous organelles in vivo. J Cell Biol 114:295-302.

Ho AM, Jain J, Rao A, Hogan PG (1994) Expression of the transcription factor NFATp in a neuronal cell line and in the murine nervous system. J Biol Chem 269:28181-28186.

Hosaka M, Hammer RE, Südhof TC (1999) A phospho-switch controls the dynamic association of synapsins with synaptic vesicles. Neuron 24:377-387.

Huang YY, Li XC, Kandel ER (1994) cAMP contributes to mossy fiber LTP by initiating both a covalently mediated early phase and macromolecular synthesis-dependent late phase. Cell 79:69-79.

Hummel T, Krukkert K, Roos J, Davis G, Klambt C (2000) Drosophila Futsch/22C10 is a MAP1B-like protein required for dendritic and axonal development. Neuron 26:357-370.

Jain J, McCaffrey PG, Miner Z, Kerppola TK, Lambert JN, Verdine GL, Curran T, Rao A (1993) The T-cell transcription factor NFATp is a substrate for calcineurin and interacts with Fos and Jun. Nature 365:352-355.

Jin Y (2002) Synaptogenesis: insights from worm and fly. Curr Opin Neurobiol 12:71-79.

Kawakami K, Noda T (2004) Transposition of the Tol2 element, an Ac-like element from the Japanese medaka fish Oryzias latipes, in mouse embryonic stem cells. Genetics 166:895-899.

Klee CB, Crouch TH, Krinks MH (1979) Calcineurin: a calcium- and calmodulin-binding protein of the nervous system. Proc Natl Acad Sci USA 76:6270-6273.

Kullberg RW, Lentz TL, Cohen MW (1977) Development of the myotomal neuromuscular junction in Xenopus laevis: an electrophysiological and fine-structural study. Dev Biol 60:101-129.

Kunz J, Hall MN (1993) Cyclosporin A, FK506 and rapamycin: more than just immunosuppression. Trends Biochem Sci 18:334-338.

Lautermilch NJ, Spitzer NC (2000) Regulation of calcineurin by growth cone calcium waves controls neurite extension. J Neurosci 20:315-325.

Liu J, Farmer JD, Lane WS, Friedman J, Weissman I, Schreiber SL (1991) Calcineurin is a common target of cyclophilin-cyclosporin A and FKBPFK506 complexes. Cell 66:807-815.

Liu YC, Storm DR (1989) Dephosphorylation of neuromodulin by calcineurin. J Biol Chem 264:12800-12804.

Lonart G, Schoch S, Kaeser PS, Larkin CJ, Südhof TC, Linden DJ (2003) Phosphorylation of RIM $1 \alpha$ by PKA triggers presynaptic long-term potentiation at cerebellar parallel fiber synapses. Cell 115:49-60.

Lonze BE, Ginty DD (2002) Function and regulation of CREB family transcription factors in the nervous system. Neuron 35:605-623.

Lyons WE, George EB, Dawson TM, Steiner JP, Snyder SH (1994) Immunosuppressant FK506 promotes neurite outgrowth in cultures of PC12 cells and sensory ganglia. Proc Natl Acad Sci USA 91:3191-3195.

Meiri KF, Pfenninger KH, Willard MB (1986) Growth-associated protein, GAP-43, a polypeptide that is induced when neurons extend axons, is a component of growth cones and corresponds to pp46, a major polypeptide of a subcellular fraction enriched in growth cones. Proc Natl Acad Sci USA 83:3537-3541.

Miesenbock G, De Angelis DA, Rothman JE (1998) Visualizing secretion and synaptic transmission with $\mathrm{pH}$-sensitive green fluorescent proteins. Nature 394:192-195.

Mombaerts P, Wang F, Dulac C, Chao SK, Nemes A, Mendelsohn M, Edmondson J, Axel R (1996) Visualizing an olfactory sensory map. Cell $87: 675-686$.
Mons N, Guillou JL, Jaffard R (1999) The role of $\mathrm{Ca}^{2+} /$ calmodulinstimulable adenylyl cyclases as molecular coincidence detectors in memory formation. Cell Mol Life Sci 55:525-533.

Nakata T, Terada S, Hirokawa N (1998) Visualization of the dynamics of synaptic vesicle and plasma membrane proteins in living axons. J Cell Biol 140:659-674

Namiki S, Tomida T, Tanabe M, Iino M, Hirose K (2003) Intracellular delivery of glutathione $S$-transferase into mammalian cells. Biochem Biophys Res Commun 305:592-597.

Nishinakamura R, Matsumoto Y, Uochi T, Asashima M, Yokota T (1997) Xenopus FK 506-binding protein homolog induces a secondary axis in frog embryos, which is inhibited by coexisting BMP 4 signaling. Biochem Biophys Res Commun 239:585-591.

Nonet ML (1999) Visualization of synaptic specializations in live C. elegans with synaptic vesicle protein-GFP fusions. J Neurosci Methods 89:33-40.

Orellana SA, McKnight GS (1992) Mutations in the catalytic subunit of cAMP-dependent protein kinase result in unregulated biological activity. Proc Natl Acad Sci USA 89:4726-4730.

Pieribone VA, Shupliakov O, Brodin L, Hilfiker-Rothenfluh S, Czernik AJ, Greengard P (1995) Distinct pools of synaptic vesicles in neurotransmitter release. Nature 375:493-497.

Poser S, Storm DR (2001) Role of $\mathrm{Ca}^{2+}$-stimulated adenylyl cyclases in LTP and memory formation. Int J Dev Neurosci 19:387-394.

Ressler KJ, Sullivan SL, Buck LB (1994) Information coding in the olfactory system: evidence for a stereotyped and highly organized epitope map in the olfactory bulb. Cell 79:1245-1255.

Risinger C, Bennett MK (1999) Differential phosphorylation of syntaxin and synaptosome-associated protein of $25 \mathrm{kDa}$ (SNAP-25) isoforms. J Neurochem 72:614-624.

Rodriguez I, Feinstein P, Mombaerts P (1999) Variable patterns of axonal projections of sensory neurons in the mouse vomeronasal system. Cell 97:199-208.

Roos J, Hummel T, Ng N, Klambt C, Davis GW (2000) Drosophila Futsch regulates synaptic microtubule organization and is necessary for synaptic growth. Neuron 26:371-382.

Sato-Yoshitake R, Yorifuji H, Inagaki M, Hirokawa N (1992) The phosphorylation of kinesin regulates its binding to synaptic vesicles. J Biol Chem 267:23930-23936.

Scheiffele P, Fan J, Choih J, Fetter R, Serafini T (2000) Neuroligin expressed in nonneuronal cells triggers presynaptic development in contacting axons. Cell 101:657-669.

Schiebler W, Jahn R, Doucet JP, Rothlein J, Greengard P (1986) Characterization of synapsin I binding to small synaptic vesicles. J Biol Chem 261:8383-8390.

Skene JH (1989) Axonal growth-associated proteins. Annu Rev Neurosci 12:127-156.

Song HJ, Poo MM (1999) Signal transduction underlying growth cone guidance by diffusible factors. Curr Opin Neurobiol 9:355-363.

Südhof TC, Czernik AJ, Kao HT, Takei K, Johnston PA, Horiuchi A, Kanazir SD, Wagner MA, Perin MS, De Camilli P, Greengard P (1989) Synapsins: mosaics of shared and individual domains in a family of synaptic vesicle phosphoproteins. Science 245:1474-1480.

Takei Y, Harada A, Takeda S, Kobayash K, Terada S, Noda T, Takahashi T, Hirokawa N (1995) Synapsin I deficiency results in the structural change in the presynaptic terminals in the murine nervous system. J Cell Biol 131:1789-1800.

Togashi H, Abe K, Mizoguchi A, Takaoka K, Chisaka O, Takeichi M (2002) Cadherin regulates dendritic spine morphogenesis. Neuron 35:77-89.

Tokuoka H, Yoshida T, Matsuda N, Mishina M (2002) Regulation by GSK-3 $\beta$ of the arborization field and maturation of retinotectal projection in zebrafish. J Neurosci 22:10324-10332.

tom Dieck S, Sanmarti-Vila L, Langnaese K, Richter K, Kindler S, Soyke A, Wex H, Smalla KH, Kampf U, Franzer JT, Stumm M, Garner CC, Gundelfinger ED (1998) Bassoon, a novel zinc-finger CAG/glutaminerepeat protein selectively localized at the active zone of presynaptic nerve terminals. J Cell Biol 142:499-509.

Ulloa L, Dombradi V, Diaz-Nido J, Szucs K, Gergely P, Friedrich P, Avila J (1993) Dephoshorylation of distinct sites on microtubule-associated protein MAP1B by protein phosphatases $1,2 \mathrm{~A}$ and $2 \mathrm{~B}$. FEBS Lett 330:85-89.

Umemori H, Linhoff MW, Ornitz DM, Sanes JR (2004) FGF22 and its close 
relatives are presynaptic organizing molecules in the mammalian brain. Cell 118:257-270.

Vardinon-Friedman H, Bresler T, Garner CC, Ziv NE (2000) Assembly of new individual excitatory synapses: time course and temporal order of synaptic molecule recruitment. Neuron 27:57-69.

Vassar R, Chao SK, Sitcheran R, Nunez JM, Vosshall LB, Axel R (1994) Topographic organization of sensory projections to the olfactory bulb. Cell 79:981-991.

Wilson SW, Ross LS, Parrett T, Easter SSJ (1990) The development of a simple scaffold of axon tracts in the brain of the embryonic zebrafish, Brachydanio rerio. Development 108:121-145.

Yan G, Chen X, Bancroft C (1994) A constitutively active form of CREB can activate expression of the rat prolactin promoter in non-pituitary cells. Mol Cell Endocrinol 101:R25-R30.

Yoshida T, Mishina M (2003) Neuron-specific gene manipulations in transparent zebrafish embryos. Methods Cell Sci 25:15-23.

Yoshida T, Ito A, Matsuda N, Mishina M (2002) Regulation by protein kinase A switching of axonal pathfinding of zebrafish olfactory sensory neurons through the olfactory placode-olfactory bulb boundary. J Neurosci 22:4964-4972.

Zhai RG, Vardinon-Friedman H, Cases-Langhoff C, Becker B, Gundelfinger ED, Ziv NE, Garner CC (2001) Assembling the presynaptic active zone: a characterization of an active one precursor vesicle. Neuron 29:131-143. 